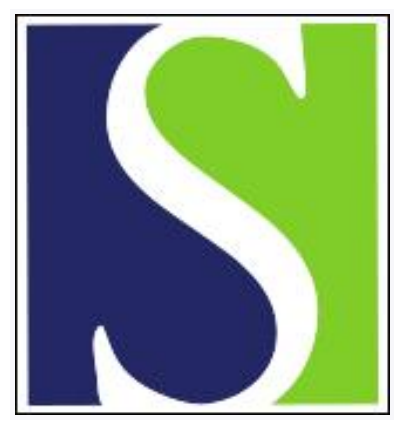

Scand J Work Environ Health 2017;43(5):494-503

https://doi.org/10.5271/sjweh.3644

Published online: 10 May 2017, Issue date: 01 Sep 2017

Appraisal of levels and patterns of occupational exposure to 1,3-butadiene

by Scarselli A, Corfiati M, Di Marzi D, lavicoli S

Levels and extents of occupational exposures to 1,3-butadiene are not yet extensively evaluated. The present study is the first Italian study that evaluated exposure to 1,3-butadiene basing on a large sample of measurements and using several statistical analysis methods to identify high-risk exposure situations. The present study also intends to contribute to raise public awareness about occupational exposure levels to 1,3-butadiene.

Affiliation: Istituto Nazionale per l'Assicurazione contro gli Infortuni sul Lavoro (INAIL), Dipartimento di Medicina, Epidemiologia, Igiene del Lavoro ed Ambientale, Viale Stefano Gradi, 55, 00143 Roma, Italy. a.scarselli@inail.it

Key terms: 1,3-butadiene; exposure assessment; occupational exposure; occupational health; surveillance system

This article in PubMed: www.ncbi.nlm.nih.gov/pubmed/28489219

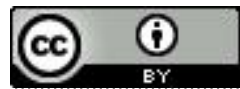




\title{
Appraisal of levels and patterns of occupational exposure to 1,3-butadiene
}

\author{
by Alberto Scarselli, MS, ${ }^{1}$ Marisa Corfiati MD, PhD, ${ }^{1}$ Davide Di Marzio, BS, ${ }^{1}$ Sergio lavicoli MD, PhD ${ }^{1}$
}

\begin{abstract}
Scarselli A, Confiati M, Di Marzio D, lavicoli S. Appraisal of levels and patterns of occupational exposure to 1,3-butadiene. Scand J Work Environ Health. 2017;43(5):494-503. doi:10.5271/sjweh.3644
\end{abstract}

\begin{abstract}
Objectives 1,3-butadiene is classified as carcinogenic to human by inhalation and the association with leukemia has been observed in several epidemiological studies. The aim of this study was to evaluate data about occupational exposure levels to 1,3-butadiene in the Italian working force.
\end{abstract}

Methods Airborne concentrations of 1,3-butadiene were extracted from the Italian database on occupational exposure to carcinogens in the period 1996-2015. Descriptive statistics were calculated for exposure-related variables. An analysis through linear mixed model was performed to determine factors influencing the exposure level. The probability of exceeding the exposure limit was predicted using a mixed-effects logistic model. Concurrent exposures with other occupational carcinogens were investigated using the two-step cluster analysis.

Results The total number of exposure measurements selected was 23885 , with an overall arithmetic mean of $0.12 \mathrm{mg} / \mathrm{m}^{3}$. The economic sector with the highest number of measurements was manufacturing of chemicals (18 744). The most predictive variables of the exposure level resulted to be the occupational group and its interaction with the measurement year. The highest likelihood of exceeding the exposure limit was found in the manufacture of coke and refined petroleum products. Concurrent exposures were frequently detected, mainly with benzene, acrylonitrile and ethylene dichloride, and three main clusters were identified.

Conclusions Exposure to 1,3-butadiene occurs in a wide variety of activity sectors and occupational groups. The use of several statistical analysis methods applied to occupational exposure databases can help to identify exposure situations at high risk for workers' health and better target preventive interventions and research projects.

Key terms exposure assessment; occupational health; surveillance system.

1,3-butadiene is a colorless gas with a mild gasoline-like odor. Several international agencies and governmental organizations, including the International Agency for Research on Cancer (IARC), have classified this chemical agent as carcinogenic to human by inhalation (1). According to the European Commission's classification, 1,3-butadiene may cause cancer and it is suspected of causing genetic defects. Low concentrations of 1,3-butadiene are usually found in the ambient air as a result of combustion processes, mainly from the cigarette smoke and motor vehicle exhaust. Environmental contamination may occur in the surroundings of oil refineries and chemical manufacturing plants (2). At industrial level, 1,3-butadiene is used as a chemical intermediate to produce many chemicals, mostly in the manufacturing of rubber, plastics, and their copolymers, as well as in the production of resins. Occupational exposure can also occur in petroleum refining, or in less character- ized work settings such as, eg, secondary lead smelting, water treatment, production of raw material for nylon, and in the use of agricultural fungicides or fossil fuels.

In the 1980s, the Occupational Safety and Health Administration (OSHA) estimated 52000 US workers were exposed to 1,3-butadiene (excluding those exposed in the polymer industry), and the exposure level ranged from $0.06-39 \mathrm{ppm}\left(0.13-86.2 \mathrm{mg} / \mathrm{m}^{3}\right)$ (3). In the European Union (EU), epidemiological evaluations estimate d31 553 workers were exposed to 1,3-butadiene above the background level, 6618 of whom were in Italy $(4,5)$.

The association between occupational exposure to 1,3-butadiene and the occurrence of cancers of haematolymphatic organs, mainly leukemia, was demonstrated in large occupational cohort studies (6). The epidemiological evidence supports a linear dose-response relationship with no threshold for cancer effects, in accordance with mechanistic data $(7,8)$. OSHA recommends a short-term

1 Department of Occupational and Environmental Medicine, Epidemiology and Hygiene, Italian Workers' Compensation Authority (INAIL), Rome, Italy.

Correspondence to: Alberto Scarselli, Istituto Nazionale per l'Assicurazione contro gli Infortuni sul Lavoro (INAIL), Dipartimento di Medicina, Epidemiologia, Igiene del Lavoro ed Ambientale, Viale Stefano Gradi, 55, 00143 Roma, Italy. [E-mail: a.scarselli@inail.it] 
(15-minute) exposure limit (STEL) of 5 ppm (or $11 \mathrm{mg}$ / $\mathrm{m}^{3}$ ) and a permissible exposure limit (PEL) of $1 \mathrm{ppm}$ (or $2.2 \mathrm{mg} / \mathrm{m}^{3}$ ). A threshold limit value (TLV) of $2 \mathrm{ppm}$ (or $4.4 \mathrm{mg} / \mathrm{m}^{3}$ ), expressed as an 8-hour time-weighted average (TWA), is also provided by the American Conference of Governmental and Industrial Hygienists (ACGIH). No occupational exposure level for 1,3-butadiene has been established yet by law in Italy as in most of other EU countries, but an occupational EU limit value of 2.2 $\mathrm{mg} / \mathrm{m}^{3}(1 \mathrm{ppm})$ is under consideration for insertion in the Annex III of the Directive $n^{\circ} 2004 / 37 /$ EC on the protection of workers from carcinogenic risks at work. This exposure level would correspond to an additional risk of 10-3 of leukemia death among workers and is considered to be too conservative. Another matter of concern is represented by the concurrent exposure to other occupational carcinogens in several activity sectors. Previous studies demonstrated that exposures to benzene, styrene and dimethyl-dithiocarbamate do not affect the dose-related induction of leukemia by 1,3-butadiene (9-11). Nevertheless the existence of multiple exposure patterns should be taken into great account, both at individual and group level, when assessing the compliance with exposure limit values or the protection standards at work.

In Italy, since 1996, employers are required to record in a register workers' exposure to carcinogenic chemicals classified by the EU, including 1,3-butadiene, with the aim of monitoring and controlling the exposure risk (12). This register is transmitted both to inspection authorities and, for epidemiological purposes, to the Italian workers' compensation authority (INAIL).

The aim of this study is to depict levels and patterns of exposure to 1,3-butadiene across different economic sectors in Italy based on the INAIL national exposure dataset.

\section{Methods}

\section{Data gathering}

All exposures to 1,3-butadiene collected in the Italian Information System on Occupational Exposure to Carcinogens (SIREP) and recorded in the period 1996-2015 were considered for the study. SIREP is a relational database whose design and contents have been fully described elsewhere (12). In brief, Italian law requires that employers collect data on workers' exposures to carcinogens and report this information to INAIL every three years. The reporting is mandatory for carcinogens classified as 1A and 1B by the new Globally Harmonized System of classification (GHS) currently adopted by EU (1A, known to be carcinogenic; 1B, presumed to be carcinogenic), corresponding to 1 and 2 categories respectively in the old system of Classification, Labeling and
Packaging (CLP). Employers are required to complete a standardized report that includes personal and occupational data of exposed employees, carcinogenic agents to which they are exposed and exposure levels (in term of intensity, frequency and duration), besides the economic activity sector and the workforce size. In particular, one or more exposure measurements are recorded for each worker and period of job. Employers are responsible for the exposure measurement procedures and air sampling methods to be carried out in accordance with European standards which provide technical guidance to implement an air monitoring strategy (13).

\section{Data selection}

A first analysis of data completeness led to the exclusion of 4530 exposure situations, which had incomplete measurement data or were missing occupational information. A total of 23885 measurements that refer to 10546 exposure situations to 1,3-butadiene were available, and 4019 exposures were measured more than once over time. Indeed, some exposure situations (ie, working activities involving exposure to 1,3-butadiene) were measured several times over the years, as a results, eg, of a change in working conditions. The sampling type (personal or environmental) was almost unknown (98\% of cases), while the analytical method performed for the measurements was not always available (42\%). All measurements were weighted on 8 hours. Data transmitted to the INAIL only concerned the TWA- 8 value, ie, the average result over a typical workday of the sampling procedure. Measurements $(\mathrm{N}=2374)$ that were below the analytical limit of detection (LOD) were replaced with the LOD value divided by two (LOD/2) (14). The most frequently reported LOD was $<0.001 \mathrm{ppm}(0.002 \mathrm{mg} /$ $\mathrm{m}^{3}$ ), representing $35 \%$ of measurements below the LOD value. Measurements provided in ppm were converted to $\mathrm{mg} / \mathrm{m}^{3}$ using the standard conversion factor derived at $25^{\circ} \mathrm{C}$ and 1 atmosphere of pressure $\left(1 \mathrm{ppm}=2.21 \mathrm{mg} / \mathrm{m}^{3}\right)$. International standard classifications were used to code economic activity sectors (Nomenclature statistique des Activités économiques dans la Communauté Europénne, NACE, revision 1) and occupations (International Standard Classification of Occupations, ISCO-88).

Descriptive statistical analyses were carried out to estimate the arithmetic mean (AM), the geometric mean (GM) and the median (M) of exposure levels, the standard deviation (SD), the geometric standard deviation (GSD) and the $25-75^{\text {th }}$ interquartile range (IQR). A sample size of 75 measurements was set as the minimum number required to perform reliable descriptive statistics.

\section{Estimating exposed workers}

The number of workers potentially exposed to 1,3-butadi- 
ene was estimated for those economic activity sectors better characterized in the database, where the percentage of reported workforce (exposed together with non-exposed) was consistent, ie, $\geq 1 \%$ of the total sector work force $\left(\mathrm{RW}_{\mathrm{i}} / \mathrm{W}_{\mathrm{i}} \geq 1 \%\right.$, where $\mathrm{RW}_{\mathrm{i}}=$ SIREP reported work force, $\mathrm{W}_{\mathrm{i}}=$ total work force, and $\mathrm{i}=\mathrm{i}$-th economic sector) and with more than three firms recorded in SIREP. The total sector work force was estimated through the national statistics from the Italian Institute for Statistics (ISTAT) (15). For the selected activity sectors, the number of workers potentially exposed to 1,3-butadiene was reconstructed using the percentage of exposed workers in relation to both the work force size of firms recorded in SIREP and the national statistics on work force (ie, $\mathrm{PE}_{\mathrm{i}}=\mathrm{W}_{\mathrm{i}} \times\left(\mathrm{E}_{\mathrm{i}} / \mathrm{RW}_{\mathrm{i}}\right)$, where $\mathrm{PE}_{\mathrm{i}}=$ potentially exposed workers, $\mathrm{W}_{\mathrm{i}}=\mathrm{ISTAT}$ total workforce, $\mathrm{RW}_{\mathrm{i}}=\mathrm{SIREP}$ reported workforce and $\mathrm{E}_{\mathrm{i}}=\mathrm{SIREP}$ exposed workers). SIREP exposed workers $\left(\mathrm{E}_{\mathrm{i}}\right)$ is the total number of workers having 1,3-butadiene exposure measurements recorded in SIREP (including those with levels below the LOD), for the i-th activity sector. In order to obtain economic activity sectors encoded in a comparable manner to the coding system of ISTAT census, the NACE revision 2 international classification was used.

\section{Mixed-effects model}

A mixed-effects model with random firm-specific intercepts was adopted to evaluate the association between exposure variables and 1,3-butadiene air concentration. In order to uniform the results of the study and produce more robust estimates, regression analysis was restricted to data recorded in the sectors and groups selected for the descriptive statistics ( $\mathrm{N}=21$ 741). A non-parametric oneway analysis of variance (ANOVA) using the KruskalWallis test was applied to detect and identify variables influencing the exposure level, and only variables statistically significant at the $\mathrm{P}<0.05$ were included in the model. All independent variables (fixed effects) in the model were categorical except for the measurement year: economic activity sector (NACE revision 1 codes), firm size $(1-9,10-19,20-49,50-99, \geq 100$ workers), geographical location of the firm (by Italian region), worker's gender, and occupation (ISCO-88 codes). Exposure measurements were natural log-transformed because data were positively skewed and approximately log-normal distributed. A P-value $\leq 0.05$ was considered as statistically significant to retain variables in the model, and the restricted maximum likelihood method was used as estimation method. The Akaike Information Criterion (AIC) was applied to achieve the best fitting model.

The mixed-effects model is described by the following equation:

$$
\left.\ln \left(\mathrm{Y}_{\mathrm{i}}\right)=\beta_{0}+\sum \text { (fixed effects }\right)+(\text { firm effect })_{\mathrm{i}}+(\text { (error })_{\mathrm{i}}
$$

for $\mathrm{i}=1, . ., \mathrm{n}$ (firms), where $Y_{i}$ is the exposure level and $\beta_{0}$ is an overall intercept representing the mean background exposure level (log-transformed) when all factors are equal to zero. The model assumptions are: random effect corresponding to firm (firm effect) is approximately normally distributed with a mean of 0 and a variance of $\sigma_{\mathrm{B}}^{2}$; residual (error) is approximately normally distributed with a mean of 0 and a variance of $\sigma_{\mathrm{W}}{ }^{2}$; and (firm effect) and (error) are statistically independent. A variance components structure was used as the covariance matrix.

Eta squared $\left(\eta^{2}\right)$ was computed for each specific effect to measure the degree of association using the following formula:

$$
\eta^{2}=\mathrm{F}_{\text {effect }}\left(\mathrm{DF}_{\text {effect }}\right) / \mathrm{F}_{\text {effect }}\left(\mathrm{DF}_{\text {effect }}\right)+\mathrm{DF}_{\text {error }}
$$

\section{Predictive probability analysis}

The probability of exceeding half of the OSHA PEL value (ie, $1.1 \mathrm{mg} / \mathrm{m}^{3}$ ) for 1,3-butadiene exposures was modelled using mixed-effect logistic regression. The model is described by the following equation:

$$
\operatorname{logit}\left(\mathrm{p}_{\mathrm{ij}}\right)=\ln \left(\mathrm{p}_{\mathrm{ij}} / 1-\mathrm{p}_{\mathrm{ij}}\right)=\beta_{0}+\beta_{1}(\text { year })_{\mathrm{ij}}+\beta_{2}(\text { activity }
$$

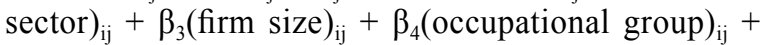
$\mathrm{b}_{\mathrm{i}}(\text { firm })_{\mathrm{i}}+\left(\right.$ (error $_{\mathrm{ij}_{\mathrm{j}}}$

for $i=1, . ., n$ (firms), $j=1, . ., h_{i}$ (workers in the $i_{\text {th }}$ firm), where $p_{i j}$ represents the probability of the sample to exceed the PEL $/ 2$ value, $\beta_{0}$ is an overall intercept, $\beta_{1}, \beta_{2}$, $\beta_{3}$, and $\beta_{4}$ the fixed effects. The model assumptions are the same as the mixed-effects model. A variance components structure was used as the covariance matrix. The year of measurement was introduced in the model as a continuous variable to test the presence of a time trend.

\section{Co-exposures analysis}

The frequency of concurrent exposures with 1,3-butadiene was evaluated for main co-exposure agents and described by economic sector. Main co-exposure agents were those that recorded $\geq 500$ exposed workers. Associations between exposures were assessed by use of the Spearman's correlation coefficient $\left(\mathrm{r}_{\mathrm{s}}\right)$. To explore patterns of exposure to multiple agents among workers exposed to 1,3-butadiene, a cluster analysis based on the SPSS twostep clustering method was performed, using the Bayesian information criterion (BIC) as clustering method and the log-likelihood as distance measure. This type of cluster analysis has been designed to be particularly suited for handling large datasets, and it has the advantage of not requiring to set a priori the number of clusters.

The data were collected routinely as an institutional 
activity and were analyzed anonymously using IBM SPSS Statistics v. 22 (IBM Corp, Armonk, NY, USA).

\section{Results}

\section{Descriptive statistics}

Overall, the mean level (AM) of exposure to 1,3-butadiene was $0.12 \mathrm{mg} / \mathrm{m}^{3}\left(\mathrm{SD}=0.37, \mathrm{GM}=0.03 \mathrm{mg} / \mathrm{m}^{3}\right.$ $\left.\mathrm{GSD}=6.73 \mathrm{M}=0.03 \mathrm{mg} / \mathrm{m}^{3}, \mathrm{IQR}=0.007-0.097\right)$, and was higher amongmen $\left(0.12 \mathrm{mg} / \mathrm{m}^{3}, 97 \%\right.$ of exposed workers) than women $\left(0.05 \mathrm{mg} / \mathrm{m}^{3}, 3 \%\right)$. The sector most at risk for higher levels of exposure was rubber and plastic products manufacturing $\left(\mathrm{GM}=0.17 \mathrm{mg} / \mathrm{m}^{3}\right)$, even if most of the exposures were gathered in the manufacture of chemicals $(\mathrm{N}=18$ 744) where, also, the few 1,3-butadiene-exposed women were employed. The occupational group with the highest level for 1,3-butadiene exposure, regardless of the economic sector, was "building structure cleaners" $\left(\mathrm{GM}=0.11 \mathrm{mg} / \mathrm{m}^{3}\right)$, even if with a low number of measurements $(\mathrm{N}=145)$. The distribution by activity sector (NACE codes) and occupational group

Table 1. Distribution of mean levels of 1,3-butadiene exposure with variability metrics by activity sector and occupational group. Only sectors and groups with $\geq 75$ exposure measurements are shown. [ $\mathrm{N}=$ number of TWA-8 exposure measurements $\left(\mathrm{mg} / \mathrm{m}^{3}\right) ; A M=a r i t h m e t i c$ mean; SD=standard deviation; GM=geometric mean; GSD=geometric standard deviation; M=median; IQR=interquartile range: $25^{\text {th }}-75^{\text {th }}$ percentile; NEC=not elsewhere classified].

\begin{tabular}{|c|c|c|c|c|c|c|c|}
\hline Activity sector (NACE Rev 1 code) / Occupational group (ISC0-88 code) & $\mathrm{N}$ & AM & SD & GM & GSD & M & IQR \\
\hline Extraction of crude petroleum and natural gas (11) & 616 & 0.06 & 0.09 & 0.01 & 7.76 & 0.01 & $0.002-0.069$ \\
\hline Mechanical engineers (2145) & 78 & 0.01 & 0.01 & 0.004 & 3.06 & 0.002 & $0.002-0.011$ \\
\hline Well drillers and borers and related workers (8113) & 177 & 0.13 & 0.11 & 0.05 & 6.96 & 0.07 & $0.019-0.250$ \\
\hline Petroleum- and natural-gas-refining-plant operators (8155) & 222 & 0.03 & 0.05 & 0.01 & 6.69 & 0.002 & $0.001-0.053$ \\
\hline Manufacture of coke, refined petroleum products (23) & 1698 & 0.34 & 0.96 & 0.06 & 13.61 & 0.18 & $0.020-0.250$ \\
\hline Petroleum- and natural-gas-refining-plant operators (8155) & 1475 & 0.39 & 1.03 & 0.08 & 12.48 & 0.18 & $0.050-0.320$ \\
\hline Chemical-processing-plant operators NEC (8159) & 179 & 0.01 & 0.05 & 0.003 & 2.76 & 0.003 & $0.001-0.007$ \\
\hline Manufacture of chemicals and chemical products (24) & 18744 & 0.09 & 0.25 & 0.02 & 5.80 & 0.03 & $0.007-0.071$ \\
\hline Research and development managers (1237) & 485 & 0.03 & 0.11 & 0.01 & 6.08 & 0.007 & $0.002-0.040$ \\
\hline Chemists (2113) & 1026 & 0.08 & 0.14 & 0.03 & 4.52 & 0.03 & $0.020-0.071$ \\
\hline Electrical engineers (2143) & 135 & 0.05 & 0.11 & 0.01 & 5.34 & 0.01 & $0.007-0.033$ \\
\hline Mechanical engineers (2145) & 768 & 0.08 & 0.18 & 0.02 & 5.68 & 0.01 & $0.005-0.046$ \\
\hline Chemical engineers (2146) & 176 & 0.01 & 0.11 & 0.003 & 2.97 & 0.002 & $0.002-0.002$ \\
\hline Chemical and physical science technicians (3111) & 208 & 0.05 & 0.18 & 0.01 & 5.99 & 0.008 & $0.002-0.030$ \\
\hline Electrical engineering technicians (3113) & 725 & 0.05 & 0.10 & 0.01 & 5.09 & 0.01 & $0.002-0.055$ \\
\hline Mechanical engineering technicians (3115) & 1000 & 0.06 & 0.14 & 0.02 & 5.29 & 0.02 & $0.007-0.055$ \\
\hline Physical and engineering science technicians n.e.c. (3119) & 81 & 0.07 & 0.14 & 0.02 & 5.36 & 0.02 & $0.007-0.055$ \\
\hline Safety, health and quality inspectors (3152) & 428 & 0.04 & 0.07 & 0.01 & 4.40 & 0.01 & $0.004-0.049$ \\
\hline Technical and commercial sales representatives (3415) & 300 & 0.06 & 0.14 & 0.03 & 3.92 & 0.03 & $0.013-0.070$ \\
\hline Trade brokers (3421) & 114 & 0.03 & 0.05 & 0.01 & 4.52 & 0.007 & $0.002-0.042$ \\
\hline Stock clerks (4131) & 742 & 0.06 & 0.10 & 0.02 & 5.06 & 0.03 & $0.004-0.055$ \\
\hline Fire-fighters (5161) & 427 & 0.04 & 0.10 & 0.02 & 6.01 & 0.04 & $0.002-0.055$ \\
\hline Agricultural- or industrial-machinery mechanics and fitters (7233) & 92 & 0.07 & 0.15 & 0.02 & 5.66 & 0.03 & $0.002-0.053$ \\
\hline Electronics mechanics, fitters and servicers (7242) & 228 & 0.09 & 0.20 & 0.03 & 4.73 & 0.02 & $0.007-0.070$ \\
\hline Petroleum- and natural-gas-refining-plant operators (8155) & 4914 & 0.09 & 0.21 & 0.03 & 4.88 & 0.03 & $0.011-0.086$ \\
\hline Chemical-processing-plant operators n.e.c. (8159) & 5410 & 0.15 & 0.38 & 0.03 & 6.40 & 0.04 & $0.011-0.111$ \\
\hline Power-production plant operators (8161) & 560 & 0.04 & 0.04 & 0.02 & 4.60 & 0.02 & $0.004-0.055$ \\
\hline Plastic-products machine operators (8232) & 107 & 0.003 & 0.01 & 0.001 & 2.87 & 0.001 & $0.000-0.001$ \\
\hline Manufacture of rubber and plastic products (25) & 136 & 0.32 & 0.25 & 0.17 & 4.90 & 0.25 & $0.078-0.500$ \\
\hline Plastic-products machine operators (8232) & 109 & 0.36 & 0.26 & 0.23 & 2.84 & 0.50 & $0.078-0.500$ \\
\hline Manufacture of machinery and equipment n.e.c (29). & 148 & 0.19 & 0.06 & 0.16 & 1.87 & 0.22 & $0.150-0.221$ \\
\hline Motor vehicle mechanics and fitters (7231) & 106 & 0.20 & 0.04 & 0.19 & 1.57 & 0.22 & $0.221-0.221$ \\
\hline Manufacture of motor vehicles, trailers and semi-trailers (34) & 181 & 0.02 & 0.03 & 0.01 & 4.08 & 0.004 & $0.003-0.050$ \\
\hline Motor vehicle mechanics and fitters (7231) & 75 & 0.01 & 0.01 & 0.004 & 1.98 & 0.004 & $0.003-0.004$ \\
\hline Electricity, gas, steam and hot water supply (40) & 143 & 0.20 & 0.56 & 0.002 & 35.06 & 0.002 & $0.000-0.030$ \\
\hline Petroleum- and natural-gas-refining-plant operators (8155) & 103 & 0.15 & 0.42 & 0.001 & 25.02 & 0.000 & $0.000-0.009$ \\
\hline Construction (45) & 309 & 0.17 & 0.21 & 0.04 & 13.31 & 0.14 & $0.011-0.199$ \\
\hline Bricklayers and stonemasons (7122) & 75 & 0.20 & 0.08 & 0.17 & 2.10 & 0.15 & $0.144-0.309$ \\
\hline Other business activities (74) & 621 & 0.18 & 0.42 & 0.04 & 7.42 & 0.08 & $0.004-0.250$ \\
\hline Building structure cleaners (7143) & 136 & 0.17 & 0.12 & 0.13 & 2.23 & 0.08 & $0.075-0.318$ \\
\hline Petroleum- and natural-gas-refining-plant operators (8155) & 190 & 0.25 & 0.02 & 0.25 & 1.06 & 0.25 & $0.250-0.250$ \\
\hline Chemical-processing-plant operators n.e.c. (8159) & 104 & 0.15 & 0.32 & 0.01 & 7.39 & 0.004 & $0.004-0.004$ \\
\hline Sewage and refuse disposal, sanitation and similar activities (90) & 1097 & 0.17 & 0.45 & 0.03 & 5.45 & 0.02 & $0.012-0.127$ \\
\hline Chemists (2113) & 99 & 0.30 & 0.43 & 0.09 & 6.96 & 0.20 & $0.022-0.386$ \\
\hline Chemical-processing-plant operators n.e.c. (8159) & 509 & 0.24 & 0.57 & 0.05 & 5.77 & 0.03 & $0.016-0.174$ \\
\hline Incinerator, water-treatment and related plant operators (8163) & 213 & 0.01 & 0.01 & 0.01 & 2.52 & 0.01 & $0.008-0.017$ \\
\hline
\end{tabular}


(ISCO-88) is shown in table 1. Regarding job tasks, the work activity suffering higher levels of exposure was the molding activity among machine operators of plastic products $\left(\mathrm{GM}=0.28 \mathrm{mg} / \mathrm{m}^{3}, 0.5 \%\right.$ of exposed workers of which were $33 \%$ women).

The time trend of the mean level (GM) of exposure to 1,3-butadiene was tested by linear regression analysis. A decrease of GM was shown over time (with a coefficient of -0.002 per year) although not statistically significant $(\mathrm{P}=0.05)$. In recent years $(2010-2013)$, the annual average of 1,3-butadiene measurements reported to SIREP was more constant (about 1600).

Overall, about $24 \%$ of measurements exceeded the value of $0.1 \mathrm{mg} / \mathrm{m}^{3}$, but this percentage varied widely among activity sectors. Apart from chemical manufacturing (54\%), elevated exposure levels $\left(>1.0 \mathrm{mg} / \mathrm{m}^{3}\right.$, about half of the OSHA PEL value) occurred in prevalence in coke and refined petroleum product manufacturing $(29 \%)$. Considering the distribution of exposures within each sector (figure 1), the petroleum industry had more than $15 \%$ of exposure measurements $>0.5 \mathrm{mg} / \mathrm{m}^{3}$. The rubber and plastic product manufacturing had more than $57 \%$ of exposure measurements $>0.1 \mathrm{mg} / \mathrm{m}^{3}$ but no value was $>1.0 \mathrm{mg} / \mathrm{m}^{3}$, while about $11 \%$ of exposures were $>1.0 \mathrm{mg} / \mathrm{m}^{3}$ in the production and distribution of electricity, gas and steam.

\section{Estimating exposed workers}

Overall, 8151 workers were found to be potentially at risk of 1,3-butadine exposure, grouped in the manufac- ture of other organic basic chemicals (6233 exposed workers, of which $95 \%$ were men), which includes activity such as the thermal cracking and distillation, and in the refined petroleum product manufacturing sector (1918 exposed workers, all men), which comprises mainly oil refineries. In percentage terms with respect to the workforce of each sector, $61 \%$ of men and $21 \%$ of women were exposed in other organic basic chemicals maufacturing, while $15 \%$ of men in refined petroleum products manufacturing were exposed. In other sectors, such as the manufacture of rubber and plastic products, the data were insufficient to perform reliable statistics.

\section{Mixed-effects model}

In the mixed-effects model, exposure variables and all crossed interactions (two by two) were analyzed to test independent effects. Variables and interactions not significant at $\mathrm{P}<0.05$ were removed step by step from the model. The final model (the lowest value for AIC) had four significant interaction components, the most significant of which was between the occupational group and measurement year $\left(\eta^{2}=0.023\right)$. The main effect of measurement year was left in the final model, although not significant, since significant interactions between other variables (ie, occupational group or firm size) can mask its main effect. In the final model between- and within-firm variances were $\sigma_{\mathrm{B}}{ }^{2}=0.38$ and $\sigma_{\mathrm{W}}{ }^{2}=1.75$ respectively. The fixed-effects of the model explained $51 \%$ of the variance $\left(\mathrm{R}^{2}\right)$ in

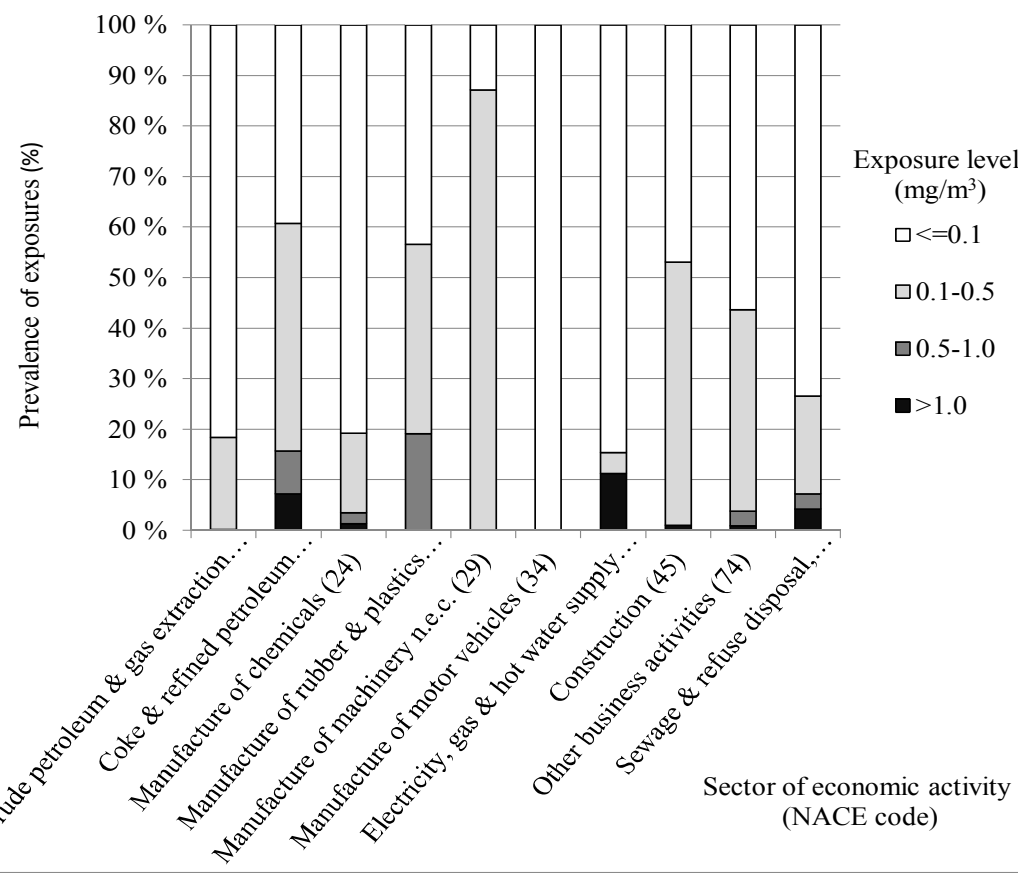

Figure 1. Distribution of prevalence (\%) of 1,3-butadiene exposures by exposure levels within each activity sector (labelled with a short description and NACE code). 
Table 2. Final mixed effects model for 1,3-butadiene exposure [DF=degrees of freedom; 2=partial eta squared]

\begin{tabular}{lrrrr}
\hline Effect & DF & $\eta^{2}$ & F-test & P-value \\
\hline Occupational group & 22 & 0.022 & 21.98 & $<0.0001$ \\
Occupational group a & 24 & 0.023 & 21.48 & $<0.0001$ \\
Measurement year & & & & \\
Occupational group a (firm size) & 28 & 0.007 & 5,23 & $<0.0001$ \\
Measurement year a (firm size) & 4 & 0.006 & 33.98 & $<0.0001$ \\
Geographical location & 12 & 0.006 & 10.39 & $<0.0001$ \\
Firm size & 4 & 0.006 & 33.74 & $<0.0001$ \\
Activity sector a & 10 & 0.005 & 10.64 & $<0.0001$ \\
(geographical location) & & & & \\
Activity sector & 5 & 0.001 & 5,15 & 0.010 \\
Measurement year & 1 & 0.000 & 1.42 & 0.233 \\
\hline A Amulicative
\end{tabular}

${ }^{a}$ A multiplicative interaction (crossed) of variables.

the observed exposure data. Summary statistics for the final model are presented in table 2 . The solution for fixed effects of the model that contains only main effects is presented in table 3 .

\section{Predictive probability analysis}

The fixed-effects activity sector and firm size were both significant at $\mathrm{P}<0.05$. For the evaluation of predicted probabilities, the measurement year was set to 2007 because it was the year corresponding to the largest number of measurements ( $17 \%$ of the total), given the definitive emanation of the legislation on the recording of occupational exposures (Ministry Decree ${ }^{\circ}$ 155/2007). It was observed a decreasing time trend in the likelihood of exposure above half the PEL value, even if not significant $\left(\beta_{1}=-0.02, \mathrm{P}=0.08\right)$. The occupational group was incorporated in the model since exposure among occupations within a sector may be not homogeneous. The highest probability values were found in coke and refined petroleum product manufacturing (0.08) and production of electricity, gas and steam (0.11). As regards occupational group, about $60 \%$ of exposure categories resulted in a predicted probability $<0.05$, with no relevant exposure risk differences. The circumstance of being employed in a small-sized firm (20-49 workers) or in a micro-firm (1-9 workers) yielded higher predicated probabilities. The estimated means of the probabilities by firm size is shown in figure 2 .

\section{Co-exposures analysis}

No more than $5.6 \%$ of recorded workers was found to be exposed exclusively to 1,3-butadiene, almost all employed in the chemical industry. Most relevant concurrent exposures to 1,3-butadiene occurred with benzene ( $72 \%$ of workers are exposed to both agents) mainly in petroleum extraction ( $99 \%$ of exposed work-
Table 3. Estimates of fixed effects for variables influencing 1,3-butadiene exposure in the mixed model containing only main effects. Last category was the baseline for each variable. Main effect of geographical location is not shown. [NEC=not elsewhere classified; SE=standard error.]

\begin{tabular}{|c|c|c|c|}
\hline Effect & Estimate $^{\text {a }}$ & SE & P-value \\
\hline Intercept & 19.15 & 5.66 & 0.00 \\
\hline $\begin{array}{l}\text { Measurement year } \\
\text { Activity sector (NACE rev } 1 \text { code) }\end{array}$ & -0.05 & 0.00 & 0.00 \\
\hline $\begin{array}{l}\text { Extraction of crude petroleum and } \\
\text { natural gas (11) }\end{array}$ & 0.32 & 1.27 & 0.80 \\
\hline $\begin{array}{l}\text { Manufacture of coke, refined petroleum } \\
\text { products (23) }\end{array}$ & 2.40 & 1.16 & 0.05 \\
\hline $\begin{array}{l}\text { Manufacture of chemicals and chemical } \\
\text { products (24) }\end{array}$ & 0.99 & 0.96 & 0.31 \\
\hline $\begin{array}{l}\text { Manufacture of rubber and plastic } \\
\text { products }(25)\end{array}$ & 1.01 & 1.38 & 0.47 \\
\hline $\begin{array}{l}\text { Manufacture of machinery and } \\
\text { equipment NEC (29). }\end{array}$ & 0.81 & 1.63 & 0.62 \\
\hline $\begin{array}{l}\text { Manufacture of motor vehicles, trailers } \\
\text { and semi-trailers (34) }\end{array}$ & -0.78 & 1.82 & 0.67 \\
\hline $\begin{array}{l}\text { Electricity, gas, steam and hot water } \\
\text { supply (40) }\end{array}$ & -0.52 & 1.45 & 0.72 \\
\hline Construction (45) & 1.44 & 1.25 & 0.26 \\
\hline Other business activities (74) & 0.76 & 1.44 & 0.60 \\
\hline $\begin{array}{l}\text { Sewage \& refuse disposal, sanitation, } \\
\text { similar activities ( } 90) \\
\text { Occupational group (ISCO-88 code) }\end{array}$ & 0 & & \\
\hline $\begin{array}{l}\text { Research and development managers } \\
(1237)\end{array}$ & -0.02 & 0.45 & 0.97 \\
\hline Chemists (2113) & -0.02 & 0.45 & 0.97 \\
\hline $\begin{array}{l}\text { Electrical engineers (2143) } \\
\text { Mechanical enaineers }(2145)\end{array}$ & -0.62 & 0.46 & 0.18 \\
\hline Mechanical engineers (2145) & -0.05 & 0.45 & 0.91 \\
\hline Chemical engineers (2146) & -0.15 & 0.46 & 0.74 \\
\hline $\begin{array}{l}\text { Chemical and physical science } \\
\text { technicians (3111) }\end{array}$ & -0.18 & 0.45 & 0.68 \\
\hline Electrical engineering technicians (3113) & -0.07 & 0.45 & 0.87 \\
\hline $\begin{array}{l}\text { Mechanical engineering technicians } \\
(3115)\end{array}$ & -0.15 & 0.45 & 0.74 \\
\hline $\begin{array}{l}\text { Physical and engineering science } \\
\text { technicians NEC ( } 3119)\end{array}$ & -0.28 & 0.47 & 0.56 \\
\hline $\begin{array}{l}\text { Safety, health and quality inspectors } \\
(3152)\end{array}$ & -0.32 & 0.45 & 0.48 \\
\hline $\begin{array}{l}\text { Technical and commercial sales } \\
\text { representatives (3415) }\end{array}$ & -0.07 & 0.45 & 0.87 \\
\hline Trade brokers (3421) & -1.31 & 0.47 & 0.00 \\
\hline Stock clerks (4131) & -0.49 & 0.45 & 0.28 \\
\hline Fire-fighters (5161) & -0.29 & 0.45 & 0.53 \\
\hline Bricklayers and stonemasons (7122) & 0 & & \\
\hline Building structure cleaners (7143) & 1.30 & 1.86 & 0.49 \\
\hline $\begin{array}{l}\text { Motor vehicle mechanics and fitters } \\
\text { (7231) }\end{array}$ & 0 & & \\
\hline $\begin{array}{l}\text { Agric. or industrial-machinery } \\
\text { mechanics and fitters (7233) }\end{array}$ & -0.77 & 0.47 & 0.10 \\
\hline $\begin{array}{l}\text { Electronics mechanics, fitters and } \\
\text { servicers (7242) }\end{array}$ & -0.37 & 0.46 & 0.42 \\
\hline $\begin{array}{l}\text { Well drillers and borers and related } \\
\text { workers (8113) }\end{array}$ & 0.50 & 0.48 & 0.30 \\
\hline $\begin{array}{l}\text { Petroleum- and natural-gas-refining- } \\
\text { plant operators (8155) }\end{array}$ & 0.04 & 0.45 & 0.94 \\
\hline $\begin{array}{l}\text { Chemical-processing-plant operators } \\
\text { NEC (8159) }\end{array}$ & 0.03 & 0.45 & 0.94 \\
\hline $\begin{array}{l}\text { Power-production plant operators } \\
\text { (8161) }\end{array}$ & -0.44 & 0.45 & 0.33 \\
\hline $\begin{array}{l}\text { Incinerator, water-treatment \& related } \\
\text { plant operators (8163) }\end{array}$ & 0.17 & 0.67 & 0.81 \\
\hline $\begin{array}{l}\text { Plastic-products machine operators } \\
\text { (8232) }\end{array}$ & 0 & . & \\
\hline \multicolumn{4}{|l|}{ Firm size (workers) } \\
\hline $1-9$ & 0.49 & 0.84 & 0.57 \\
\hline $10-19$ & 2.15 & 1.14 & 0.07 \\
\hline $20-49$ & 1.37 & 0.67 & 0.05 \\
\hline $50-99$ & 0.86 & 0.67 & 0.21 \\
\hline$\geq 100$ & 0 & & \\
\hline
\end{tabular}

${ }^{\text {a Natural logarithm of exposure value }}$ 
ers of that sector) and refining (73\%), with acrylonitrile ( $45 \%$ of workers) mainly in the rubber and plastic industry $(88 \%)$, and ethylene dichloride (34\% of workers) mainly in the sewage and refuse disposal sector $(72 \%)$. A relevant number of workers exposed to 1,3-butadiene were also simultaneously exposed to propylene oxide, ethylene oxide and acrylamide ( $8 \%$ of workers). As many as 267 different combinations of exposure to the nine main co-exposure agents were detected within the activity sectors. High positive correlations were found between 1,3-butadiene and benzene $\left(\mathrm{r}_{\mathrm{s}}=0.32\right)$ and acrylonitrile $\left(r_{s}=0.33\right)$, and therefore more likely came from the same source of exposure. Figure 3 shows agents that contribute to the most common concurrent exposures and the percentage of workers sharing the exposures, with the indication of the $r_{s}$ value for each agent. By using the two-step cluster analysis, the following three main clusters of co-exposures were identified: (i) acrylamide, acrylonitrile and isoprene (which includes $28.3 \%$ of identified co-exposures); (ii) ethylene dichloride, ethylene oxide, propylene oxide and vinyl chloride (30.7\%); (iii) benzene and polycyclic aromatic hydrocarbons (PAH) (41\%). All the three clusters were found in the chemical industry, namely in the manufacture of other organic basic chemicals; cluster 1 of co-exposures was reported also in the manufacture of electrical machinery, cluster 2 in construction (insulating work), cluster 3 in the extraction of crude petroleum and natural gas, and both clusters 2 and 3 in the sector of sewage and refuse disposal. The corresponding index of cohesion and separation of clusters found was good ( silhouette index $=0.5$ ).

\section{Discussion}

Despite that the carcinogenicity of 1,3-butadiene has been demonstrated so far in experimental and epidemiological studies, a relevant number of workers are still exposed to this chemical. Our study, based on exposure registries, estimates that in Italy occupational exposure can involve, in the chemical industry and oil refineries (sectors best characterized in the SIREP database), about 8000 workers, more than previously estimated by the Carcinogen Exposure (CAREX) database (5). Moreover, information is provided on different levels and patterns of exposure to 1,3-butadiene, to be used in programming of future preventive interventions at the national level. In particular, this study is the first, to our knowledge, in applying cluster analysis on exposure registry data in order to identify the main concurrent exposures to other carcinogens in the 1,3-butadiene-exposed workforce and their distribution across economic activity sectors.

The occupational exposure to 1,3-butadiene mainly

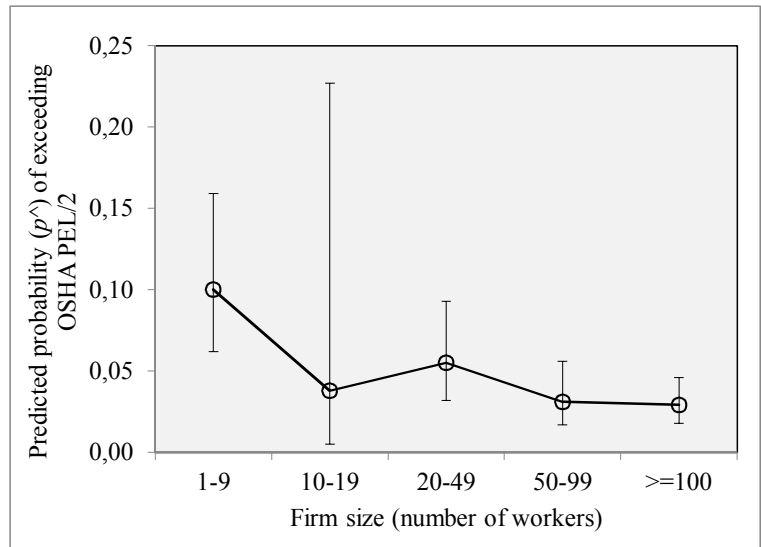

Figure 2. Distribution of estimated marginal means and $95 \%$ confidence intervals for the predicted probability of exceeding OSHA PEL/2 (ie, 1.1 $\mathrm{mg} / \mathrm{m}^{3}$ ) for 1,3-butadiene exposures by firm size.

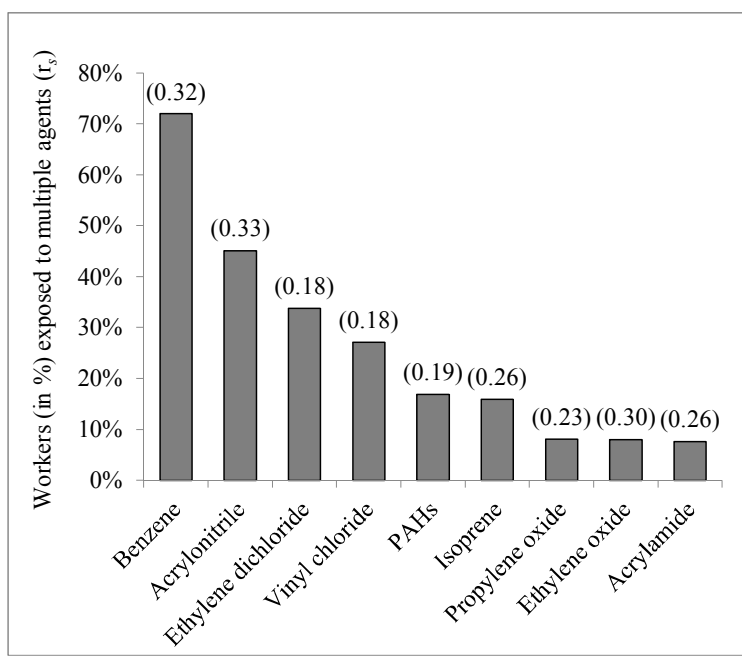

Figure 3. Distribution of workers (in \%) exposed simultaneously to 1,3-butadiene and to other occupational carcinogens, provided with the Spearman's correlation coefficient (rs).

occurred in the manufacture of chemicals and chemical products, including the manufacture of other organic basic chemicals and the manufacture of synthetic rubber. In this sector, indeed, a low mean exposure level was measured, comparable to the exposure limit suggested for the general population (ie, that causes 10-6 excess risk of leukemia), with no substantial differences among occupations $(16,17)$. On the other hand, a wide range of co-exposure patterns were reported among chemical industry workers. The carcinogens for which the workers were concurrently exposed often have mechanisms of action other than 1,3-butadiene, even if most of 
them are genotoxic and several (eg, benzene) affect the same target organ $(18,19)$. Moreover, the exposure level to 1,3-butadiene in our dataset seems to increase with increasing levels of other carcinogens $\left(r_{s}>0\right)$, as previously reported in other studies $(11,20)$. Given the multifactorial and multistage nature of carcinogenesis, it is not possible to estimate the separate contribution of each agent in the determination of individual cancer cases. However, a cohort study among workers exposed to a combination of ethylene oxide, ethylene dichloride, ethylene hydrin and ethylene, showed a significant mortality excess from cancer presumably imputable to a combined effect of ethylene oxide and ethylene dichloride (21). Starting from the national exposure database, three more common patterns of exposure clustering were observed, all widely represented in the manufacture of other organic basic chemicals, while another exposure group looked prevalent in the production of synthetic rubber but without constituting a cluster (1,3-butadiene, ethylene dichloride, benzene and vinyl chloride). Further research is recommended to compare cancer excess risk associated with different clusters of chemical exposures in order to identify particular high-risk groups of workers. Furthermore, particular attention should be focused on the presence of female workers exposed in the chemical industry due to the possible adverse effects on newborns, even if the few studies of occupationally exposed women have been inconclusive $(22,23)$.

Mean exposure levels to 1,3-butadiene in rubber and plastic products manufacturing and in the production of refined petroleum products were higher than in the chemical industry. Rubber industry workers have been traditionally exposed to 1,3-butadiene because of its use in the manufacture of synthetic rubber products. The job task most at risk was found in the molding activity among plastic-product machine operators, about half of which were exposed to 1,3-butadiene concentrations $>0.5 \mathrm{mg} / \mathrm{m}^{3}$. The mixed-effects model actually shows, among main effects, occupation as the most important determinant for 1,3-butadiene exposure level. In addition, the multivariate model reveals a strong interaction effect between measurement year and occupation $\left(\eta^{2}=0.023\right)$, indicating substantial changes over time in reporting exposure depending on the occupation. Taken as a whole, these findings confirm that, while general exposure levels are decreasing over time, exposure risk tends to mainly affect certain occupations and job tasks.

Our analysis suggested a higher health risk in the manufacture of refined petroleum products and the production of electric energy. In these sectors, a greater probability to surpass the value of $1.0 \mathrm{mg} / \mathrm{m}^{3}$ of 1,3-butadiene concentration was found and confirmed by the predictive probability analysis. In oil refineries, the vast majority of exposed workers, mostly petroleum and natural gas refining plant operators, are concurrently exposed to benzene, and our data confirm the presence of an association between exposure to benzene and 1,3-butadiene in certain occupational groups analyzed by a recent study on two refineries and an oil harbor (24). Even if the concentrations of 1,3-butadiene measured by Akerstrom and colleague in Swedish refineries are lower than that reported in our study, a common issue is represented by the exposure risk for contractors in this sector (24). In fact, in our study, higher levels of 1,3-butadiene exposure were reported among workers doing the same occupation (plant operators) for contracting firms, mainly registered in the tertiary sector (ie, other businesses activity), underlining the need of potentiate the protection for this particular group of workers.

According to our data, occupations having a considerable exposure to 1,3-butadiene include also bricklayers and stonemasons mainly engaged in insulating work, building cleaners, technicians and blue-collar workers employed in the sewage and refusal recycling plants, and mechanics and fitters working in the production of electric machinery. It should be noted that, despite their small number, these workers show exposure levels comparable to those of the occupational groups at risk previously mentioned, and similar co-exposures patterns.

Finally, 1,3-butadiene exposure was shown to be influenced by firm size with higher probability of exceeding half the OSHA's PEL value $\left(1.1 \mathrm{mg} / \mathrm{m}^{3}\right)$ in micro- and small enterprises. This finding may be due to effective technical prevention measures adopted by larger industrial groups. Lee and colleagues (25) used a similar approach to the model presented here to predict the probability of exceeding OSHA's PEL for occupational exposure to $\mathrm{PAH}$. These models were developed with the awareness that to improve the understanding of where, when, and how to control occupational exposures, it is very important to recognize the factors that most influence exposure levels (26). Nevertheless, findings presented here must be read taking into account the specific purpose for which our data were collected, mainly consisting in epidemiological surveillance instead of compliance control.

The main limitations of the SIREP database are the inhomogeneous territorial coverage and the underrepresentation of some economical activities, as already underlined in previous studies $(27,28)$. Data collection and reporting for the SIREP system is under the responsibility of the employer, and we observed that the number of exposure measurements differed by industrial sector and firm size. In particular industrial sectors and occupational groups are differently represented in this dataset. Exposure measurements were in large quantities for some industries/occupations (eg, manufacture of chemicals and chemical products, $\mathrm{N}=18$ 744), but limited for others (eg, manufacture of rubber and plastic products, $\mathrm{N}=136$ ). For this reason the reported results 
should be considered with caution. Moreover an underreporting of data for smaller firms is likely because of a lower commitment to workers' health and safety (29, 30 ). The possibility that firms which do not record or transmit data on exposures have higher exposure levels may have affected our estimates. Uncertainty may have also been introduced as a result of differences in air sampling, analytical procedures, sample collection methods (personal or stationary) and data classification. In order to increase the precision of estimates, only sectors and occupations having $>75$ measurements recorded were included in the analysis. Lowering this limit, in fact, some results showed a large variability, losing in accuracy. Furthermore, a firm random effect was included in the mixed model, since measurements reported by the same firm may be correlated with each other, mainly due to intrinsic characteristics of the notification system (a passive-type system). Other problems inherent to the use of administrative sources like the SIREP system are the original purpose of data collection (eg, complaint, compliance, research, etc.), changes in measurement techniques, and variability in environmental conditions, that may distort exposure measurements if missing (31). Lastly, only those sectors better characterized in the database were taken into account to estimate the number of workers potentially exposed. A consequence of this selection is that certain economic sectors were excluded because of the limited information on the size of reported workforce (eg, research activities and education services). The number of exposed workers in each sector was calculated assuming the same ratio between workers exposed and non-exposed in firms notifying and non-notifying the exposures data to the SIREP system. This assumption may have likely introduced further bias in the estimates.

\section{Concluding remarks}

Despite limitations on exposure levels (unreported information) and data incompleteness in some industrial sectors, an overall picture of the occupational exposure situation to 1,3-butadiene in Italy was provided, which can also be shared with other EU countries that have a similar industrial base. Moreover, the estimates here produced may be useful in conducting future industryand occupation-specific investigations. The statistical models applied in this study allow the identification of activities and occupations with different risks of 1,3-butadiene exposure. However, because exposure may not be homogeneous within sectors and groups, future work will be needed to more accurately identify the exposure risk. A more accurate risk assessment based on concentration levels and co-exposure patterns can contribute to improve epidemiological surveillance, to address prevention and health promotion programs at workplace, and to warrant equity in workers' compensation as well. Particular attention should be paid to health protection of contracted workers who often suffer high exposure levels due to doing unskilled and less warranted tasks, by improving the labor inspections systems in the sectors mainly involved.

\section{Funding}

The Italian Workers' Compensation Authority (INAIL) supported this work. The authors declare no competing interests.

\section{References}

1. International Agency for Research on Cancer (IARC). 1,3-Butadiene, Ethylene Oxide and Vinyl Halides (Vinyl Floride, Vinyl Chloride and Vinyl Bromide). Lyon: IARC; 2008. IARC monographs on the evaluation of carcinogens to humans, Vol. 97.

2. U.S. Environmental Protection Agency (EPA). Integrated Risk Information System (IRIS) on 1,3-Butadiene. Washington, DC: National Center for Environmental Assessment, Office of Research and Development; 2009.

3. National Toxicology Program (NTP). Report on Carcinogens, Thirteenth Edition: Background Document for 1,3-butadiene. Research Triangle Park, Research Triangle Park, North Carolina: Department of Health and Human Services, Public Health Service; 2014.

4. Kauppinen T, Toikkanen J, Pedersen D, Young R, Ahrens W, Boffetta $P$ et al. Occupational exposure to carcinogens in the European Union. Occup Environ Med 2000. Jan;57(1):10-8. http://dx.doi.org/10.1136/oem.57.1.10.

5. CAREX. CAREX industry specific estimates- Summary. Helsinki: Finnish Institute of Occupational Health; 1999. Available from: http://www.ttl.fi/en/ chemical_safety/carex/ Documents $/ 5$ exposures_by_agent_and_industry.pdf.

6. International Agency for Research on Cancer (IARC). Chemical agents and related occupations. Lyon: IARC; 2012. IARC monographs on the evaluation of carcinogens to humans Vol. $100 \mathrm{~F}$.

7. Kirman CR, Albertini RA, Gargas ML. 1,3-Butadiene: III. Assessing carcinogenic modes of action. Crit Rev Toxicol. 2010 Oct;40 Suppl 1:74-92. http://dx.doi.org/10.3109/1040 8444.2010.507183.

8. Sielken RL Jr, Valdez-Flores C. Butadiene cancer exposureresponse modeling: based on workers in the styrene-butadienerubber industry: total leukemia, acute myelogenous leukemia, chronic lymphocytic leukemia, and chronic myelogenous leukemia. Regul Toxicol Pharmacol. 2011 Aug;60(3):332-41. http://dx.doi.org/10.1016/j.yrtph.2011.05.001.

9. Delzell E, Sathiakumar N, Graff J, Macaluso M, Maldonado G, Matthews R; Health Effects Institute. An updated study of 
mortality among North American synthetic rubber industry workers. Res Rep Health Eff Inst. 2006 Aug;132(132):1-63.

10. Cheng H, Sathiakumar N, Graff J, Matthews R, Delzell E. 1,3-Butadiene and leukemia among synthetic rubber industry workers: exposure-response relationships. Chem Biol Interact. 2007 Mar;166(1-3):15-24. http://dx.doi. org/10.1016/j.cbi.2006.10.004.

11. Sathiakumar N, Brill I, Leader M, Delzell E. 1,3-Butadiene, styrene and lymphohematopoietic cancer among male synthetic rubber industry workers--Preliminary exposureresponse analyses. Chem Biol Interact. 2015 Nov;241:40-9. http://dx.doi.org/10.1016/j.cbi.2015.09.003.

12. Scarselli A, Montaruli C, Marinaccio A. The Italian information system on occupational exposure to carcinogens (SIREP): structure, contents and future perspectives. Ann Occup Hyg. 2007 Jul;51(5):471-8. http://dx.doi. org/10.1093/annhyg/mem022.

13. European Committee for Standardization (CEN). Workplace atmospheres-Guidance for the assessment of exposure by inhalation to chemical agents for comparison with limit values and measurement strategy, EN 689. Brussels: CEN; 1995.

14. Hornung R, Reed LD. Estimation of average concentration in the presence of nondetectable values. Appl Occup Environ Hyg. 1990;5:46-51. http://dx.doi.org/10.1080/104 7322X.1990.10389587.

15. Italian National Statistics Institute (ISTAT). $9^{\text {th }}$ Industry and Services Census. Rome: ISTAT; 2011. Available from: http:// dati-censimentoindustriaeservizi.istat.it/ (accessed 10 Jan 2017).

16. Sielken RL Jr, Valdez-Flores C. A comprehensive review of occupational and general population cancer risk: 1,3-Butadiene exposure-response modeling for all leukemia, acute myelogenous leukemia, chronic lymphocytic leukemia, chronic myelogenous leukemia, myeloid neoplasm and lymphoid neoplasm. Chem Biol Interact. 2015 Nov;241:50-8. http://dx.doi.org/10.1016/j. cbi.2015.06.009.

17. Grant RL, Haney J, Curry AL, Honeycutt M. Development of a unit risk factor for 1,3-butadiene based on an updated carcinogenic toxicity assessment. Risk Anal. 2009 Dec;29(12):1726-42. http://dx.doi.org/10.1111/j.15396924.2009.01302.x.

18. Ruchirawat M, Navasumrit P, Settachan D. Exposure to benzene in various susceptible populations: co-exposures to 1,3-butadiene and PAHs and implications for carcinogenic risk. Chem Biol Interact. 2010 Mar;184(1-2):67-76. http:// dx.doi.org/10.1016/j.cbi.2009.12.026.

19. Cemeli E, Mirkova E, Chiuchiarelli G, Alexandrova $\mathrm{E}$, Anderson D. Investigation on the mechanisms of genotoxicity of butadiene, styrene and their combination in human lymphocytes using the Comet assay. Mutat Res. 2009 May;664(1-2):69-76. http://dx.doi.org/10.1016/j. mrfmmm.2009.02.010.

20. Macaluso M, Larson R, Lynch J, Lipton S, Delzell E. Historical estimation of exposure to 1,3-butadiene, styrene, and dimethyldithiocarbamate among synthetic rubber workers. J Occup Environ Hyg. 2004 Jun;1(6):371-90. http://dx.doi.org/10.1080/15459620490452004.

21. Hogstedt C, Rohlén O, Berndtsson BS, Axelson O, Ehrenberg L. A cohort study of mortality and cancer incidence in ethylene oxide production workers. Br J Ind Med.1979 Nov;36(4):276-80.

22. Sathiakumar N, Delzell E. A follow-up study of women in the synthetic rubber industry: study methods. Chem Biol Interact. 2007 Mar;166(1-3):25-8. http://dx.doi. org/10.1016/j.cbi.2006.11.005.

23. Albertini RJ, Sram RJ, Vacek PM, Lynch J, Rossner P, Nicklas JA et al. Molecular epidemiological studies in 1,3-butadiene exposed Czech workers: female-male comparisons. Chem Biol Interact. 2007 Mar;166(1-3):6377._http://dx.doi.org/10.1016/j.cbi.2006.07.004.

24. Akerstrom M, Almerud P, Andersson EM, Strandberg B, Sallsten G. Personal exposure to benzene and 1,3-butadiene during petroleum refinery turnarounds and work in the oil harbour. Int Arch Occup Environ Health. 2016 Nov;89(8):1289-97. http://dx.doi.org/10.1007/s00420-0161163-1.

25. Lee DG, Lavoué J, Spinelli JJ, Burstyn I. Statistical Modeling of Occupational Exposure to Polycyclic Aromatic Hydrocarbons Using OSHA Data. J Occup Environ Hyg. 2015;12(10):729-42. http://dx.doi.org/10.1080/15459624.2 015.1043049 .

26. Burstyn I, Teschke K. Studying the determinants of exposure: a review of methods. Am Ind Hyg Assoc J. 1999 Jan-Feb;60(1):57-72. http://dx.doi. org/10.1080/00028899908984423.

27. Scarselli A, Binazzi A, Di Marzio D. Occupational exposure levels to benzene in Italy: findings from a national database. Int Arch Occup Environ Health. 2011 Aug;84(6):617-25. http://dx.doi.org/10.1007/s00420-011-0616-9.

28. Scarselli A, Corfiati M, Marzio DD, Iavicoli S. Evaluation of workplace exposure to respirable crystalline silica in Italy. Int J Occup Environ Health. 2014 Oct;20(4):301-7. http:// dx.doi.org/10.1179/2049396714Y.0000000078.

29. Morse T, Dillon C, Weber J, Warren N, Bruneau H, Fu R. Prevalence and reporting of occupational illness by company size: population trends and regulatory implications. Am J Ind Med. 2004 Apr;45(4):361-70. http://dx.doi.org/10.1002/ ajim. 10354 .

30. Aragón-Correa JA, Hurtado-Torres N, Sharma S, GarcíaMorales VJ. Environmental strategy and performance in small firms: a resource-based perspective. J Environ Manage. 2008 Jan;86(1):88-103. http://dx.doi.org/10.1016/j. jenvman.2006.11.022.

31. Teschke K, Olshan AF, Daniels JL, De Roos AJ, Parks $\mathrm{CG}$, Schulz $\mathrm{M}$ et al. Occupational exposure assessment in case-control studies: opportunities for improvement. Occup Environ Med. 2002 Sep;59(9):575-93. http://dx.doi. org/10.1136/oem.59.9.575.

Received for publication: 16 January 2017 